\title{
A rare existence of paragangliomas Bilateral carotid body tumors: A case report
}

\author{
Sadi Kaplan' ${ }^{1}$, Tuğba Avcı', Çetin Murat Songur ${ }^{1}$, Cavit Ceylan²
}

${ }^{1)}$ Yuksek Ihtisas Education and Research Hospital of Turkey, Department of Cardiovascular Surgery, Ankara, Turkey
${ }^{2)}$ Yuksek Ihtisas Education and Research Hospital of Turkey, Department of Urologya, Ankara, Turkey

\begin{abstract}
Carotid body tumors are rare paragangliomas and generally they have benign characters. Only $3 \%$ of all paragangliomas occur in the head and neck region. Surgical procedure of carotid body tumor has a high rate neurological morbidity because of a close comminication with neurovascular formations. We report here a very rare case of glomus tumor threated surgically.
\end{abstract}

Keywords: Carotid body tumor, bilateral, neurologic complication. 


\section{Introduction}

Carotid body tumors are rare paragangliomas and generally they have benign characters. They are originating in the paraganglionic cells of the carotid bifurcation. Their incidences are between 0.06 and 3.33 per 100,000 patient. $^{(1-2)}$ In most cases, paragangliomas are sporadic (75\%) and $\% 25$ of them are associated with hereditary paraganglioma syndrome. ${ }^{(3)}$ M ultifocal paragangliomas are rarely seen in sporadic cases (\%10-20) but they have increasing tendency to be multifocal in familial form $(\% 80) \cdot{ }^{(4-5)}$

Generally cervical paragangliomas grow slowly, but if they left untreated, they grow rapidly due to rich vascular supply and expand encircling the vascular structure and cranial nerves. Surgery is the only curative treatment in this cases however surgical management of carotid body tumor has a high rate neurovascular morbidity because of a close comminication with neurovascular formations. For the surgical planing and prognostic purposes, Shamblin classification was described for these tumors' size and invasion degree in $1971{ }^{(6)}$ We report here a very rare case of glomus tumor treated successfully with surgery.

\section{Case Report}

48 years-old male patient refered to us with the complain of bilateral painless huge neck masses. He had also obstructive sleep apne and hypopne syndrom leading to significant cyanosis for 2 years which was concurrent with neck masses. The masses diameters were $10,5 \times 8 \mathrm{~cm}$ on the left (Picture 1) side and $3 \times 3 \mathrm{~cm}$ on the right side.

Radiologic examination with USG, two and three dimential CT (Picture 2-3) and MRI demonstrated glomus tumor in which were class 3 in Shamblin Classification. There was no hormonal activity or neurologic deficit about mass compression.

\section{Material and Method}

Three days after the embolization procedure he was operated on his left side. A huge tumoral mass which was thightly encircling the releated vessels was excised from all around the internal and external carotid arteries also like hypoglossus, vagus and laryngeus recur- rens. There was no residuel mass. Histology confirmed the diagnosis of glomus tumor.

Surgery was uncomplicated. He was moved to service bad on the next day and discharged 10 days after the surgery. A mild apathy and aphasia were occured on second day of the surgery.he was cosultated to the neurology department. With corthicosteroid theraphy, the symptoms were regressed on 4. day and disapperared on 8. day. He was checked on the first month of the surgery. There were no permanent operative cranial nerve injuries and other problems about surgery. His right side surgery will be applied in a few months.

\section{Conclusion}

Carotid body tumors are very rare neoplasms and rarely seen in neck resion. In this cases, generally, clinical follow-up is advised untill the compression or hormonal activation signs due to mass were occured. Reported nerve injury rates range from $11 \%$ to $50 \%$ $(7,8,9,10)$ and has high risks with higher Shamblin class.

(1) Neuronal injuries (transient or permanent) of the vagus nerve, hypoglossal nevre and other communicated nerves and vascular injuries of the carotid artery and it's branches and surrounding veins have been associated with surgical procedure ${ }^{(8)}$, especially in larger tumors with close proximity to critical structures requiring a more complex procedure for removal.

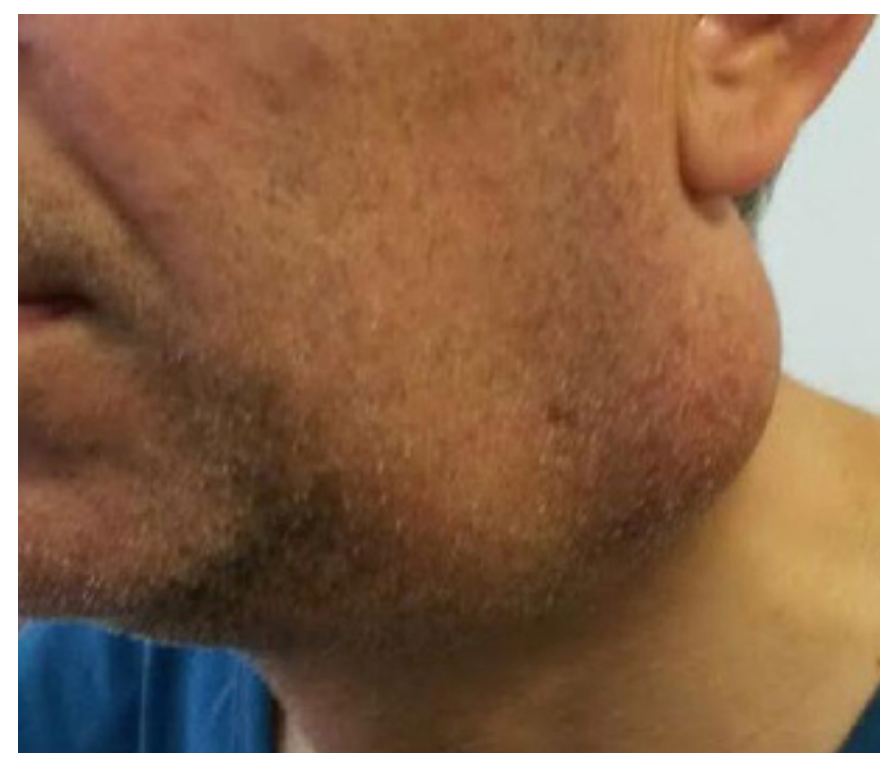

Picture 1 


\section{Results}

Surgery is the only curative therapy and accepted as a gold standart despite high risks for neurovascular complications.

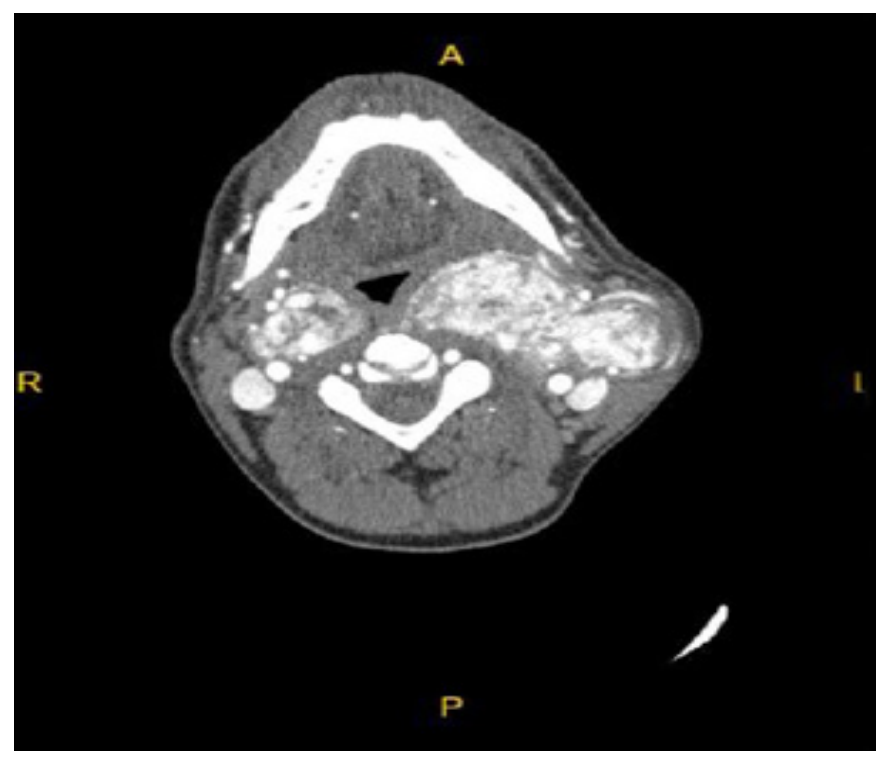

Picture 2

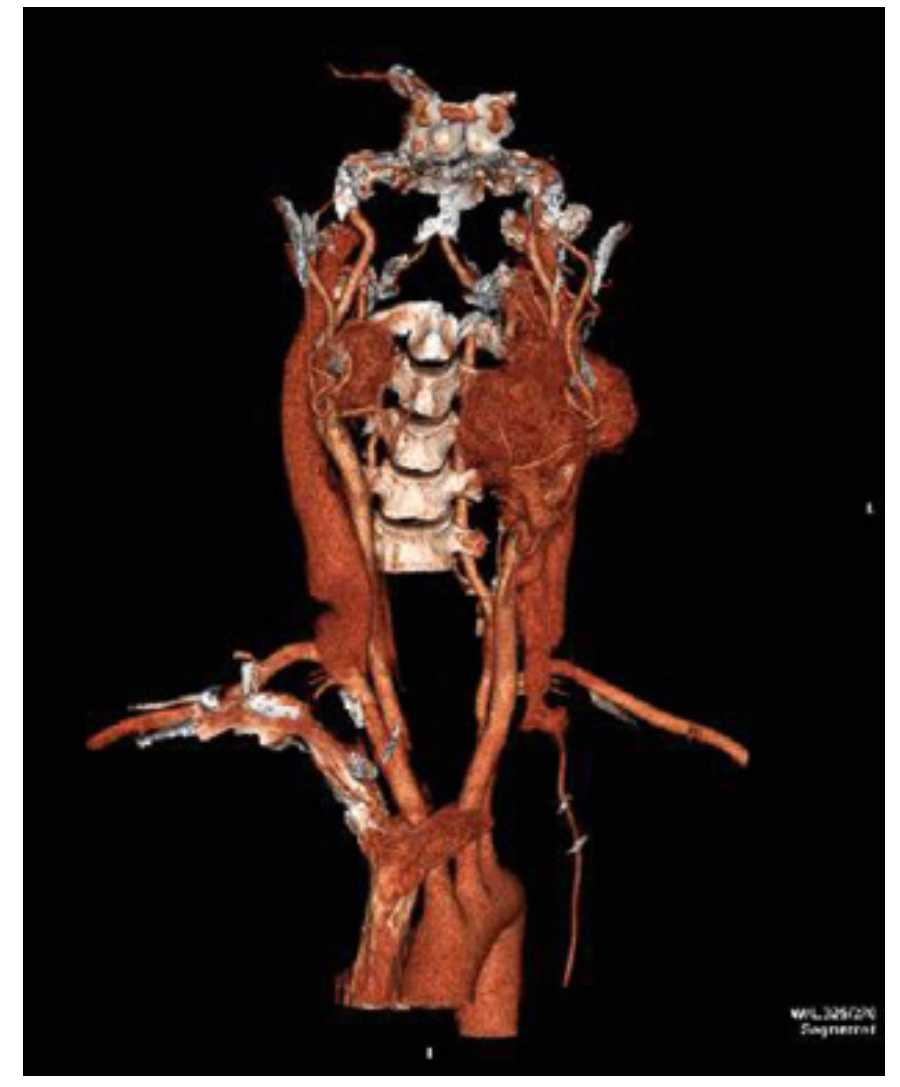

Picture 3 


\section{References}

1. Sajid MS, Hamilton G, Baker DM. A multicentre review of carotid body tumour management. Eur J Vasc Endovasc Surg. 2007; 34 (2):127-30.

2. Plukker JT, Brongers EP, Vermey A, Krikke A, van den Dungen JJ. Outcome of surgical treatment for carotid body paraganglioma. Br J Surg. 2001;88(10):1382-6.

3. Dixon JL, Atkins MD, Bohannon WT, Buckley CJ, Lairmore TC. Surgical management of carotid body tumors: a 15-year single institution experience employing an interdisciplinary approach Proc (Bayl Univ Med Cent). 2016 Jan;29(1):16-20.

4. Lee JH, Barich F, Karnell LH, Robinson RA, Zhen WK, Gantz BJ, et al. National Cancer Data Base report on malignant paragangliomas of the head and neck. Cancer. 2002;94:730-7

5. Boeckder CC, Ridder GJ, Schipper J. Paragangliomas of the head and neck: diagnosis and treatment. Fam Cancer. 2005;4:55-9.
6. Shamblin WR, Remine WH, Sheps SG, Harrison EG. Carotid body tumor (chemodectoma). Clinicopathologic analysis of ninety cases. Am J Surg 1971;122(6):732-739

7. Del Guercio L, Narese D, Ferrara D, Butrico L, Padricelli A, Porcellini M. Carotid and vagal body paragangliomas. Transl Med UniSa 2013;6(6):11- 15

8. Luna-Ortiz K, Rascon-Ortiz M, Villavicencio-Valencia V, GranadosGarcia M, Herrera-Gomez A. Carotid body tumors: review of a 20-year experience. Oral Oncol 2005;41(1):56-61.

9. Neskey DM, Hatoum G, Modh R, Civantos F, Telischi FF, Angeli SI, Weed D, Sargi Z. Outcomes after surgical resection of head and neck paragangliomas: a review of 61 patients. Skull Base 2011;21(3):171-176.

10. Davidovic LB, Djukic VB, Vasic DM, Sindjelic RP, Duvnjak SN. Diagnosis and treatment of carotid body paraganglioma: 21 year experience at a clinical center of Serbia. World J Surg Oncol 2005;3(1):10.

Received: $29 / 03 / 2016$

Accepted: 08/05/2016

Published: 20/06/2016

Disclosure and conflicts of interest:

Conflicts of interest were not reported.

\section{Corresponding author:}

Dr. Sadi Kaplan

Mail: skpn1966@hotmail.com 